\title{
Australian Journal of

\section{Billet distribution and initial establishment of sugarcane due to the planting shifts}

\author{
Wilson de Almeida Orlando Junior ${ }^{1 *}$, Carla Segatto Strini Paixão ${ }^{2}$, Murilo Aparecido Voltarelli ${ }^{4}$, Lucas \\ Augusto da Silva Girio ${ }^{3}$, Rouverson Pereira da Silva ${ }^{3}$, Haroldo Carlos Fernandes'
}

\author{
${ }^{1}$ Federal University of Viçosa, Campus Viçosa, Viçosa, MG, Brazil \\ ${ }^{2}$ University of Sorocaba,Uniso, Sorocaba, SP, Brazil \\ ${ }^{3}$ Paulista State University, Campus Jaboticabal, SP, Brazil \\ ${ }^{4}$ Federal University of São Carlos, Campus Lagoa do Sino, Buri, SP, Brazil
}

*Corresponding author: wilson.almeidaufv@gmail.com

\section{Abstract}

The increased production of sugarcane becomes increasingly dependent on mechanization mainly planting to achieve better performance, quality and cost reduction of operation. This study aimed to evaluate the mechanized planting operation of sugarcane in day and night shifts, through evaluations in the distribution of billets and early crop establishment. The mechanized planting was performed using a tractor-planter set with the chopped cane planter with two rows of fertilizer shanks spaced by 1.5 $\mathrm{m}$. A randomized blocks experimental design with 40 replications was implemented in sub-split plot scheme, considering the shifts (day and night) as main treatments, grooves (right and left) as subplots. Spacing (distribution of billets, viable buds, percentage of viable buds and consumption of buds) and time (tillering and failures in sprouting) were considered as sub-sub-plots. The results showed that the shifts had no influence on the mechanical planting operation of sugarcane neither on the quality of distribution of buds in the furrows. The initial crop establishment presented greater tillering values at 30,60 and 120 days after planting in day shift for the right furrows, as compared to night shift because of the variability in the production environment.

Keywords: mechanization, operating shifts, operation quality, planter, Saccharum spp.

Introduction

The sugarcane represents one of the great Brazilian agricultural markets. It is estimated that in the years ahead, there will be approximately $40 \%$ increase in planted area, which will reflect $100 \%$ of increase in production (Silva et al., 2014). Thus, due to the expansion of sugarcane cultivation area in Brazil, the agricultural sector is looking for options and better technologies to the field, becoming increasingly dependent on agricultural machinery, including planting, which also may lead to increase of efficiency and reduce operational costs (Peloia et al., 2010).

In this sense, the expansion of the area of sugarcane cultivation in Brazil is mainly due to the use of more robust machines to increase the speed of the planting work, apply fertilizers, distributing buds, covering buds with soil and after finishing the operation, performing the compaction of the furrows (Voltarelli et al., 2014). However, when planting is executed outside of established patterns it can influence the quality of the process, compromising its continuity (Barros and Milan, 2010), and more yet influencing tillering of sugarcane.

The mechanized planting system can largely replace the manpower in this operation, due to increasing the use of mechanized sets for planting operation that can work for longer periods during the day and night (Khedkar and Kamble, 2008). The same authors also describe that there is variation between work shifts, because at night quality standards of planting carried may decrease, resulting in failure in sprouting. Therefore, for setting up the cane fields all factors that may affect the operation and reduction of emerged tillers number such as: regulation of the planter, decompressing and soil preparation, health of plants, appropriate water content must be considered among others (Duarte Junior et al., 2008).

The planting is an activity of utmost importance because the sugarcane is considered a semi-perennial crop. Failures committed on this operation may represent up to five consecutive years of compromised productivity (Ferreira et al., 2008).

Assuming that failures occur due to the process of mechanized sugarcane's planting in both day and night shifts, influencing the quality of the planting operation, this study aimed to evaluate the mechanized planting of sugarcane in day and night shifts, through evaluation in distribution of billets and the initial establishment of culture.

Results

\section{Evaluation of mechanized sugarcane planting}

The influence of the shifts (day and night) and furrows (left and right), as well as the interaction between them was verified for the variables in the furrows after mechanical planting (Table 1). It was observed that the coefficient of variation (CV), with the exception of percentage of viable 
buds, may be considered high or very high (Pimentel-Gomes amd Garcia, 2002). This situation can cause some instability in the values of the parameters due to the high variability for that field condition. However, it is verified that the means fulfill the requirement of being equal, when considering the minimum significant difference (MSD) for each variable, since the absolute value of the difference between them was less than the MSD. It consequently determines greater security and reliability of the results.

The non-significance of variables for both factors and its interaction can be explained by the proper adjustment of the sugar-cane planter, specifically the speed of rotation of the distributor, or measurement of the billets and the adequacy of the operating speed of the mechanized set in relation to the distribution of the billets.

\section{Evaluation of mechanized sugarcane tillering}

The number of tillers and failures per meter is presented in Table 2. Analysis of data in Table 2 shows that the number of tillers per meter, which reflects the sprouting of sugarcane in the furrows at 30,60, 90 and 120 days after planting (DAP), had no influence on the shifts effects (day and night), neither on the furrows (left and right). This also occurred for the effect of number of failures per meter on the number of furrows per meter at 90 and 120 DAP.

\section{Breakdown of the interaction of the shift factor for each furrow in tillering}

According to the data in Table 2, interaction between shifts and grooves for tillering at 30,60, 90 and 120 DAP and for the number of failures per meter at 90 DAP was observed. Therefore, the breakdown of the shift interactions for each furrow in tillering was performed (Table 3). By analyzing these data, it can be observed that for P30 and P60, the right furrow has a greater number of tillers compared to the left for mechanized planting of sugarcane during day period. The P90 has a higher number of tillers in the left furrow at night operation, compared to the same furrow for operation during the day. This fact can be explained by the high variability in the physical and chemical properties of the soil, climate and soil conditions, involving temperature and available water capacity of the soil, solar radiation and finally the physiological quality of the buds.

\section{Discussion}

Voltarelli et al. (2013) reported that investment in improvement of mechanized field operations with sugarcane during day and night shifts tend to increase. However, this information is not sufficient yet for this agricultural sector, since research works may show that the management and quality of the mechanized operations can be improved. This situation is consistent with the results presented in this study, since there was no difference in the deposition of buds during the work shifts. It demonstrates that appropriate adjustments of the planter and the quality of the operation meet the standards established by the production unit.

Another important factor is the quality of sugarcane buds checked by the percentage of viable buds, which despite showing viability below $70 \%$, when the mechanized planting was occurred uniformly in both work shifts. In contrast, Cebim (2008), who evaluated the mechanized performance of sugarcane planting during the day period using the variety SP803280 and planter of chopped cane model PCP2, reported an average percentage of viable buds (left and right furrows) of $60 \%$ after passage of the tractor-planter set. This value is lower than that found in this study.

The average consumption of buds found in this study $(23 \mathrm{Mg}$ $\mathrm{ha}^{-1}$ for both shifts) can be considered high according to Beauclair and Scarpari (2006). They claimed that, it is common to have an amount of buds of $10 \mathrm{Mg} \mathrm{ha}^{-1}$ on the average for mechanized sugarcane planting. Under a favorable time condition for planting, an average of $12 \mathrm{Mg}$ $\mathrm{ha}^{-1}$ of billets per meter can be obtained. This situation is different from that presented for this study.

According to Landell et al. (2012), the average consumption of buds in mechanized planting is about $20 \mathrm{t} \mathrm{ha}^{-1}$, regardless of time of culture implantation. This result corroborates with those presented in this work, in which the consumption of buds was approximately the same, although performed in a dry season time of year. This high consumption of buds can be due to the damage during the harvesting, transportation, and planting itself (Serafim et al., 2013).

Janini (2007) found that the average total number of viable buds per meter was 12.5 and 17.5 in furrows on the left and right, respectively, in the mechanized planting of sugarcane. They also reported average of buds of $13.2 \mathrm{Mg} \mathrm{ha}^{-1}$ after day time operation. This situation is very different from that found in this work, because the amount of viable buds and the total number of buds was 25 to $50 \%$ higher, respectively, than the values reported by Janini (2007). This fact can be explained by the preventive measure taken at the production unit to obtain the desired quality in planting, because weather and other external factors were not suitable for sprouting in this season of planting (March), for varieties developed for cultivation in other soil and climate conditions at other times of the year.

It was observed that in all cases the amount of viable buds per meter was approximately 23 , which is considered within the standards. For safer and higher performance planting, it some requirements for each month and region are recommended. For example, in March, it is not common to use an amount below 16 viable buds per meter of furrow, because soon the fall and winter seasons will begin, which could compromise the sprouting of sugarcane due to drop in temperature and lack of rainfall. A distribution out of the non-standard range may seriously affect the process of sugar cane production, which may compromise the life of the cane fields, due to the large amount of failures or increase the cost of production caused by excess buds used per unit area (Barros and Milan, 2010).

The high values of the coefficient of variation was also observed (Pimentel-Gomes and Garcia, 2002), showing high variability of the data. On the other hand, interaction among the factors shift and furrows for tillering at 30,60, 90 and 120 DAP was verified for the number of failures at 90 DAP. Ripoli and Ripoli (2010) reported that the performance of mechanized planting operation of planters (chopped cane) did not present adequate distribution of billets, which can influence the initial tillering of the crop and further, failing in sprouting due the high variability of the operation. This result partially corroborates to this work, in which the distribution of billets was adequate for the planting 
Table 1. Analysis of variance and mean test for number of billets (NB), the total number of buds (TNB), number of viable buds (NVB), \% viable buds (VB), and billets consumption (BC) evaluated for mechanized planting of sugarcane at day and night shift operation.

\begin{tabular}{|c|c|c|c|c|c|}
\hline FACTORS & $\mathrm{NB}\left(\mathrm{m}^{-1}\right)$ & $\operatorname{TNB}\left(\mathrm{m}^{-1}\right)$ & $\operatorname{NVB}\left(\mathrm{m}^{-1}\right)$ & VB (\%) & $\mathrm{BC}\left(\mathrm{mg} \mathrm{ha}^{-1}\right)$ \\
\hline \multicolumn{6}{|l|}{ Shift (S) } \\
\hline Day & 15.7 & 35.0 & 23.6 & 63.9 & 23.2 \\
\hline Night & 15.2 & 37.0 & 23.3 & 65.9 & 23.2 \\
\hline \multicolumn{6}{|c|}{ Furrows (F) } \\
\hline Left & 15.7 & 37.0 & 23.8 & 65.4 & 24.1 \\
\hline Right & 15.1 & 35.0 & 23.1 & 65.4 & 23.1 \\
\hline \multicolumn{6}{|l|}{ F Test } \\
\hline $\mathrm{S}$ & $0.35^{\mathrm{ns}}$ & $1.07^{\mathrm{ns}}$ & $0.06^{\mathrm{ns}}$ & $3.95^{\mathrm{ns}}$ & $0.37^{\mathrm{ns}}$ \\
\hline $\mathrm{F}$ & $0.73^{\mathrm{ns}}$ & $1.33^{\mathrm{ns}}$ & $0.29^{\mathrm{ns}}$ & $0.31^{\mathrm{ns}}$ & $0.65^{\mathrm{ns}}$ \\
\hline$S \times F$ & $0.64^{\text {ns }}$ & $0.15^{\mathrm{ns}}$ & $0.03^{\text {ns }}$ & $0.45^{\text {ns }}$ & $0.56^{\text {ns }}$ \\
\hline \multicolumn{6}{|l|}{ MSD } \\
\hline S & 1.70 & 4.00 & 2.62 & 2.08 & 2.46 \\
\hline $\mathrm{F}$ & 1.53 & 4.00 & 3.38 & 3.48 & 2.44 \\
\hline CV (\%) & 35.11 & 35.28 & 35.52 & 10.22 & 33.39 \\
\hline
\end{tabular}

Table 2. Analysis of variance and mean test for tillering at 30,60, 90 and 120 DAP, and failure of sprouting at 90 and 120 DAP for mechanized planting of sugarcane at day and night shift operation.

\begin{tabular}{|c|c|c|c|c|c|c|}
\hline \multirow{2}{*}{ FACTORS } & \multicolumn{4}{|c|}{ Tillers $\left(\mathrm{m}^{-1}\right)$} & \multicolumn{2}{|c|}{ Failures $\left(\mathrm{m}^{-1}\right)$} \\
\hline & P30 & P60 & $\mathrm{P} 90$ & P120 & F90 & F120 \\
\hline \multicolumn{7}{|l|}{ Shift (S) } \\
\hline Day & 0.80 & 1.75 & 2.75 & 6.70 & 0.69 & 0.57 \\
\hline Night & 0.62 & 1.75 & 3.25 & 5.76 & 0.76 & 0.64 \\
\hline \multicolumn{7}{|c|}{ Furrows (F) } \\
\hline Lefts & 0.60 & 1.72 & 2.93 & 6.21 & 0.72 & 0.58 \\
\hline Right & 0.82 & 1.77 & 3.06 & 6.25 & 0.73 & 0.64 \\
\hline \multicolumn{7}{|l|}{ Test $\mathrm{F}$} \\
\hline $\mathrm{S}$ & $0.72^{\mathrm{ns}}$ & $0.00^{\mathrm{ns}}$ & $0.92^{\mathrm{ns}}$ & $0.66^{\mathrm{ns}}$ & $1.85^{\mathrm{ns}}$ & $1.30^{\mathrm{ns}}$ \\
\hline $\mathrm{F}$ & $2.83^{\mathrm{ns}}$ & $0.04^{\mathrm{ns}}$ & $0.16^{\mathrm{ns}}$ & $0.00^{\mathrm{ns}}$ & $0.17^{\mathrm{ns}}$ & $2.85^{\mathrm{ns}}$ \\
\hline$S \times F$ & $4.89^{*}$ & $5.62^{*}$ & $4.91^{*}$ & $10.76^{*}$ & $4.25^{*}$ & $2.25^{\mathrm{ns}}$ \\
\hline \multicolumn{7}{|l|}{ MSD } \\
\hline$S$ & 0.42 & 0.80 & 1.03 & 2.29 & 0.10 & 0.12 \\
\hline $\mathrm{F}$ & 0.25 & 0.45 & 0.64 & 1.31 & 0.06 & 0.06 \\
\hline CV (\%) & 189.84 & 145.52 & 109.77 & 116.95 & 47.64 & 62.64 \\
\hline
\end{tabular}

In each column, for each factor, the letters absences indicates no difference between them, by Tukey test at $p<0.05 p$ rob
the $\mathrm{F}$ test; CV: coefficient of variation, MSD: minimum significant difference among the factors by Tukey test at $p<0.05$.

Table 3. Breakdown of the interaction of the shift factor (day and night) for each furrow (left and right) in tillering at 30 DAP (P30), 60 DAP (P60), 90 DAP (P90) 120 DAP (P120), and failures at 90 DAP (F90) for mechanized planting of sugarcane at day and night shift operation.

\begin{tabular}{|c|c|c|c|}
\hline \multirow{2}{*}{ Variable } & \multirow{2}{*}{ Shift } & \multicolumn{2}{|c|}{ Furrows } \\
\hline & & Left & Right \\
\hline \multirow{2}{*}{ P30 } & Day & $0.55 \mathrm{Ba}$ & $1.05 \mathrm{Aa}$ \\
\hline & Night & $0.65 \mathrm{Aa}$ & $0.58 \mathrm{Aa}$ \\
\hline \multirow{2}{*}{ P60 } & Day & $1.45 \mathrm{Ba}$ & $2.04 \mathrm{Aa}$ \\
\hline & Night & $2.00 \mathrm{Aa}$ & $1.50 \mathrm{Aa}$ \\
\hline \multirow{2}{*}{ P90 } & Day & $3.67 \mathrm{Aa}$ & $2.82 \mathrm{Aa}$ \\
\hline & Night & $2.45 \mathrm{Ab}$ & $3.04 \mathrm{Aa}$ \\
\hline \multirow{2}{*}{ P120 } & Day & $5.60 \mathrm{Ba}$ & $7.80 \mathrm{Aa}$ \\
\hline & Night & $6.83 \mathrm{Aa}$ & $4.70 \mathrm{Bb}$ \\
\hline \multirow{2}{*}{ F90 } & Day & $0.73 \mathrm{Aa}$ & $0.80 \mathrm{Aa}$ \\
\hline & Night & $0.71 \mathrm{Aa}$ & $0.66 \mathrm{Ab}$ \\
\hline
\end{tabular}

In each column, for each factor, the same lowercase letters indicate no difference between them; and for each row, equal capital letters indicates no difference by Tukey test at $\mathrm{p}<0.05$ 
operation, but the tillering was potentially slowed by the low water content in the soil at the time of mechanized planting. Silva et al. (2012) reported that the ambient temperature, intensity of solar radiation and the water content in the soil govern the tillering at the planting time. The association of these three essential factors may assist to obtain better quality of tillering. The influence of these results on the tillering of planting can be considered the same that affected the values in this study, independent of work shifts.

The tillering has direct influence on the production of sugarcane related to varieties used at certain times of the year. This situation also has similarities to this work, since the variety was chosen for planting according to the characteristics of soil and climate to express their maximum potential of production (Bennett et al., 2011). However, as the adverse conditions were intense, the maximum potential of yield for the variety (genotype) of current was not achieved at the initial tillering of the crop.

Silva et al. (2008), worked with different cultivars (RB 72454 and IAC 862480) of sugarcane and reported that the maximum number of tillers was relatively found at 90 days after planting of both cultivars with an amount of 20 and 30 tillers, respectively, for the above mentioned cultivars. Such a situation did not occur for the conditions analyzed in this study that presented a reduced number of tillers for the same period evaluated by these authors. The tillering depends on the genetic characteristics of each variety, associated with environmental conditions to have sprouting of sugarcane (Oliveira et al., 2007). Almeida et al. (2008) observed tillering similar to that was discussed in this work when evaluated the variety RB 92-579.

Voltarelli et al. (2014) evaluated the mechanical planting process by determining the quality of this operation and verified that it was acceptable within the established standards. The present study reflects that the mechanized planting was satisfied for most of the characteristics and it was favorable to the development of the plant. The results of our study showed that there is a great change to have a better development of sugar cane using the mechanized methods, resulting in a good stand of the plants and minor failures in the sprouting.

Silva et al. (2007) evaluated the tillering after planting sugarcane and observed a similar behavior for the studied varieties (IAC 873396, IAC 912195 and IAC 915155), in which all presented a value in about 20 tillers $\mathrm{m}^{-1}$ at 90 days after planting. These results can be considered different from those of the present work, because at the same sampling/measurement period there was a much lower amount of tillering.

It can also be observed that the failures at the 90 DAP are higher for the right furrow in the day period, compared with to the night shift of mechanized planting operation. The probable explanation has the same analogy for tillering at $30,60,90$ and 120 DAP, since the low number of tillers has inverse influence on the amount of failures in the sprouting of sugarcane.

According to Croft et al. (2008), the failure percentage and average amount of failures in sprouting after planting the billets decreases with the age of sugarcane cut to obtain buds, if the physiological quality of the stems is in perfect condition. The same authors reported many factors that can affect the sprouting of sugarcane such as low vegetative vigor of the disposed billets, the incidence of pests and diseases, the age of the cane field, type of variety, weather conditions etc. These factors mainly cause sprouting faults and reduction in plant growth. The previous results like this, in part, disagreed with ours in the present study, since the quality of buds, unlike pests and diseases, was acceptable for planting, which in turn could provide better initial development.

In general, the influence of the shift factors (day and night) and furrows (left and right) can be mainly associated with the number of tillers, in which lower number of tillers represent the largest amount of failures of sprouting. Similarly, Janine (2007) and Cebim (2008) explained the low number of tillers and higher failure values like this study. They performed a biometric analysis of sugarcane buds after mechanized planting and also found high percentages of failures of sprouting, and reported that the climatic and edaphoclimatic factors, respectively, were the main responsible ones.

\section{Materials and methods}

\section{Location of experiments}

The experiment was accomplished in March 2012, in agricultural area of Tijuco farm, located in the municipality of Monte Alto, São Paulo, Brazil, within the geodesic coordinates at latitude of $21016^{\prime} 42^{\prime \prime S}$ and longitude of $48^{\circ} 24^{\prime} 21^{\prime \prime} \mathrm{W}$, with an average altitude of $620 \mathrm{~m}$, land with average slope of $6 \%$. The climate of the region is $A w$, as classified according to the second Köeppen-Geiger classification.

The experimental area had a history of sugarcane cultivation in the past six years. The land was reformed by the removal of stumps, unpacking the soil at the depth of $60 \mathrm{~cm}$, followed by a preparation with medium and light disc harrow. After these operations, soybean seeds were sown as intercrop. At the end of the soybean cycle, the harvest was performed and the amount of straw left in the field by the crop $\left(0.93 \mathrm{Mg} \mathrm{ha}^{-1}\right)$ was quantified. For the characterization of the soil fertility, 10 samples were collected for chemical analysis.

\section{Soil characterization}

The soil of the experimental area was classified as Ultisol dystrophic with medium texture (EMBRAPA, 2013). The soil composition at depth $0-20 \mathrm{~cm}$ presented $78 \%$ of clay, $6 \%$ of silt and $16 \%$ of sand. Chemical characteristics were: $\mathrm{pH}$ of $5.4\left(\mathrm{CaCl}_{2}\right) ; 17.0 \mathrm{~g} \mathrm{dm}^{-3}$ of organic matter (OM); $27.0 \mathrm{mg} \mathrm{dm}^{-3}$ of phosphorus resin (P); $1.3,26.0$ and $8.0 \mathrm{mmol} \mathrm{dm}^{-3}$ of potassium (K), calcium (Ca) and magnesium (Mg), respectively; cation exchange capacity (CEC) of $55.3 \mathrm{mmol}$ $\mathrm{dm}^{-3}$ and void space (V) equal to $64 \%$.

The soil water content was determined by collecting 160 samples, 80 samples for each period of operation (day and night) at layers with thickness varying from 0 to $15 \mathrm{~cm}$ and from 15 to $30 \mathrm{~cm}$, according the methodology recommended by EMBRAPA (1997). For the day and night period, the water content in the soil layer of $0-15 \mathrm{~cm}$ was 7.0 and $8.5 \%$ and in the depth of $15-30 \mathrm{~cm}$ was 6.5 and $9.0 \%$, respectively. 
The mechanized planting of sugarcane was performed using a tractor-planter set, composed of a tractor, model $77154 \mathrm{x}$ 2 (front wheel assisted), and a planter of chopped sugarcane with two rows and shanks of furrows spaced at $1.50 \mathrm{~m}$, PTX 7010 model. The tractor was equipped with a hydraulic system and automatic guidance for alignment of planting (autopilot), allowing for a quality of horizontal positioning around $0.025 \mathrm{~m}$. The tractor was equipped with a gauge adjusted to $2.70 \mathrm{~m}$ for operation and a gear of working, model 1B, (with average working speed of, approximately, $5.3 \mathrm{~km} \mathrm{~h}^{-1}$, for day and night shifts operation). At the time of mechanized planting, $400 \mathrm{~kg} \mathrm{ha}^{-1}$ of mineral fertilizer with the formulation of 6-30-20 (N-P-K), $100 \mathrm{~L} \mathrm{ha}^{-1}$ of syrup of imidacloprid insecticide, and $0.5 \mathrm{~L} \mathrm{ha}^{-1}$ of plant hormone were applied. This hormone is compound by kinetin, gibberellic acid and 4-indole-3-ilbutiric acid being used for favoring sprouting.

The variety of sugarcane used for planting was RB835054 with spacing of $1.50 \mathrm{~m}$ between rows. The farm technicians previously selected this variety, because it produces a number of viable buds of 18 to 23 per meter of furrow for both shifts, daytime or for night.

\section{Statistical analysis}

The experimental tests followed a randomized blocks design with 40 replications in sub-divided plots scheme, considering shifts (day and night) as main treatments, furrows (right and left) as subplots. The sub-subplots were considered (i) in space (distribution of grinding of billets; number of total and viable buds; percentage of viable buds; consumption of buds), and (ii) in time (tillering and failures). There was no need for exchanging the operator, once the time ranges considered for each shift were from 15:30 to 17:30 (daytime) and 19:30 to 21:30 (night), providing better conditions for experimental control.

\section{Measurement process}

The following variables were measured following the methodology described by Voltarelli et al. (2014). The total number of billets (NB) was recorded after the mechanical planting, counting the billets directly over four meters along the furrows. The digging of furrows was made with the help of a hoe, carefully handled to avoid damage and/or injury to the billets and the buds after the operation of mechanized planting of sugarcane. The total number of buds (TNB) was obtained by direct count as done previously along the four meters of furrows of planting (left and right). The number of viable buttons (NVB) has also been obtained by direct count, as performed prior to the total number of buds in the four meters over the furrows (left and right). All vegetative structures free from mechanical damage and pest attack were defined as viable gems.

\section{Determination of viability and consumption of buds}

The percentage of viable buds is determined by the number of buds that have not suffered attacks caused by pests and diseases and also the likely fragmentation due to impacts caused by mechanical harvesting, transport of buds to the planting area, discharges of buds to the bucket of the planter, the distribution to the furrows of planting (Janine, 2007), and was obtained using Equation (1).

$\mathrm{VB}=\left(\frac{\mathrm{NVB}}{\mathrm{NVB}+\mathrm{NUB}}\right) \times 100$

Where;

$\mathrm{VB}=\quad$ Amount of viable buds, \%;

$\mathrm{NVB}=\quad$ Number of viable buds, bud. $\mathrm{m}^{-1}$;

$\mathrm{NUB}=\quad$ Number of unviable buds, bud. $\mathrm{m}^{-1}$;

The consumption of buds used for each furrow was estimated for the two operating shifts (day and night), based on the values obtained from biometric analysis of buds (mass of grinding billets), information on the number of grinding billets per meter of furrows (left and right), and also the spacing used in mechanized planting, using Equation (2).

$\mathrm{BC}=\frac{\mathrm{m} \cdot \mathrm{NB} \cdot \mathrm{Pd}}{1000}$

Where;
$\mathrm{BC}=$
$\mathrm{M}=$
Billets consumption (mg.ha ${ }^{-1}$ );
$M=\quad$ Mass of the billets in the furrow $\left(\right.$ g.billet $\left.^{-1}\right)$;
$\mathrm{NB}=\quad$ Number of billets $\left(\right.$ billet. $\left.\mathrm{m}^{-1}\right)$;
$\mathrm{Pd}=\quad$ Planting density $\left(\mathrm{m} \cdot \mathrm{ha}^{-1}\right)$;
$1000=\quad$ Conversion factor $\left(\mathrm{mg}^{-1} \mathrm{~g}^{-1}\right)$.

\section{Evaluation of tillering}

The tillering of sugarcane sprouts was evaluated at 30,60 , 90 and 120 (P30, P60, P90 and P120, respectively) days after the operation of mechanized planting (DAP). The number of tillers was obtained by direct count of all tillers along the four meters of the furrows (left and right) for both operation shifts, day and night (Cebim, 2008). Using the same methodology, samples of space failures were taken on 90 and 120 days after planting (F90 and F120, respectively), by counting the number of failures in spacing according to the methodology described by Cebim (2008). In order to have a better experimental control, a unique evaluator for each replication performed the counting of all billets, buds, tillers and failures (units).

The data were analyzed by analysis of variance (ANOVA) of single factor by applying the F-test, at a significance level of $1 \%$ to verify the significant differences between the mean values of treatments. If a significant difference is found a Tukey test at $5 \%$ probability level is applied to compare the treatment means.

\section{Conclusion}

The shifts of operation (day and night) had no influence on mechanized planting of sugarcane, neither on the quality of distribution of buds in the furrows. Regardless of operation shift, sugarcane can be planted with quality, without affecting the parameters for a good final stand of the plants. The initial crop establishment presented greater values of tillering on 30, 60 and 120 days after planting for the day shift in the right furrow, compared to the night shift, due to the variability in the field environment. The major insight drawn from this work is that the adjustment of the planter 
equipment, along with the quality of the operation of planting, may maximize the performance of the completely mechanized process of sugarcane planting.

\section{Acknowledgements}

The authors are grateful to the the CAPES and CNPq for financial support.

\section{References}

Almeida ACS, Souza JL, Teodoro, I, Barbosa GVS, Moura Filho G, Ferreira Júnior RA (2008) Vegetative development and production of sugarcane varieties as a function of water availability and thermic units. Ciênc Agrotec. 32: 14411448.

Barros FF, Milan M (2010) Operational quality of sugar cane planting. Bragantia, 69: 221-229.

Beauclair EGF, Scarpari MS (2006) Noções fitotécnicas. In: Ripoli TCC, Ripoli MLC, Casagrandi DV, Ide BY. Planting of sugarcane: state of the art, 1rd edn. Piracicaba, Brazil.

Benett CGS, Buzetti S, Silva KS, Teixeira Filho MCM, Garcia CMP, Maestrelo PR (2011) Yield and development of plant cane and ratoon cane as related to manganese rates and sources. R Bras Ci Solo 35: 1661-1667.

Cebim GJ (2008) Mechanized planting of sugarcane (Saccharum spp.): operational and economic performance. MSc. Thesis, Univ of São Paulo, São Paulo, Brazil:

Croft BJ, Magarey RC, Allsopp PG, Cox MC; Willcox TG, Milford BJ, Wallis ES (2008) Sugarcane smut in Queensland: arrival and emergency response. Aust Plant Pathol. 37: 26-34.

Duarte Junior JB, Garcia RF, Coelho FC, Amim, RT (2008) Tractor-implement performance in sugarcane under notillage and conventional planting systems. R Bras Eng Agríc Ambiental. 12: 653-658.

Claessen MEC, Barreto WO, Paula JL, Duarte, MN (1997). Manual of methods and soil analysis, 2rd edn. Rio de Janeiro, Brazil, BR: Empresa Brasileira de Pesquisa Agropecuária.

Santos, HG (2013). Brazilian system of soil classification, 3rd edn. Brasília, Brazil, BR. Empresa Brasileira de Pesquisa Agropecuária.

Ferreira MC, Werneck CF, Furuhashi S, Leite GJ (2008) Treatment of sugarcane stem to control pineapple rottenness in conjugated spraying together with the mechanized planting. Eng Agríc. 28: 263-273.

Janine DA (2007) Economic and operational analysis of mechanized planting of sugarcane (Saccharum spp.). MSc. Thesis, Univ of São Paulo, São Paulo, Brazil

Khedkar MB, Kamble AK (2008) Evaluation of mechanized planting of sugarcane. IAEJ. 1(2): 136-139.

Landell MDA, Campana M, Figueiredo $P$, Xavier M, Anjos ID, Dinardo-Miranda LL, Scarpari MS, Garcia JC, Bidóia MAP, Silva DN, Mendonça JR, Kanthack RAD, Campos MF, Brancalião SR, Petri RH, Miguel PEM (2012) System of multiplication of sugarcane with use of pre-budded billets (PBB), originating from individual shoots, 1rd edn. Ribeirão Preto, Brazil. IAC.
Oliveira RA, Daros E, Zambon JLC, Weber H, Ido OT, Bespalhok-Filho JC, Zuffellato-Ribas KC, Silva DKT (2007) Leaf area in three sugar-cane cultivars and its relationship with biomass production. Pesq Agropec Trop. 37: 71-76.

Peloia PR, Milan M, Romanelli TL (2010) Capacity of the mechanical harvesting process of sugarcane billets. Sci Agric. 67:619-623.

Pimentel-Gomes F, Garcia CH (2002) Statistics applied to agronomic and forest experiments: exposure with examples and orientation of app use, Brazil, BR: Piracicaba: FEALQ.

Rípoli ML, Rípoli TC (2010) Evaluation of five sugar cane planters. Eng Agríc. 30: 1110-1122.

Serafim LGF, Stolf $R$, Silva, JR, Silva LCF, Maniero MA, Bassinelo, Al (2013) Influence of mechanized planting on sprouting index of sugarcane. STAB. 31: 22-25.

Silva MA, Arantes MT, Rhein AFL, Gava GJC, Kolln OT (2014) Yield potential of sugarcane under drip irrigation in function of varieties and crop cycles. R Bras Eng Agríc Ambient. 18: 241-249.

Silva MA, Gava GJC, Caputo MM, Pincelli RP, Jerônimo EM, Cruz JCS (2007) Use of plant growth regulators as improvers of tillering and of productivity in sugarcane ratoon. Bragantia. 66: 545-552.

Silva MA, Jeronimo EM, Lúcio AD (2008) Height of cut and harvest period effects on tillering and yield of sugarcane. Pesq Agropec Bras. 43: 979-986.

Silva TGF, Moura MSB, Zolnier S, Carmo JFA, Souza LSB (2012). Biometrics of the sugarcane shoot during irrigated ratoon cycle in the Submedio of the Vale do São Francisco. Rev Ciênc Agron. 43: 500-509.

Voltarelli MA, Silva RP, Rosalen DL, Zerbato C, Cassia MA (2013) Quality of performance of the operation of sugarcane mechanized planting in day and night shifts. Aust J Crop Sci. 7: 1396-1406.

Voltarelli MA, Silva RP, Zerbato C, Silva VFA, Cavichili FA (2014) Agronomic capability of mechanized sugarcane planting. Aust J Crop Sci. 8: 1448-1460. 